Öpik conjectures that what we now see may be only the metagalaxy-merely a step in the hierarchy of physical systems -and that the observed expansion may refer only to this limited, although large, material system; conditions may be different in other parts of the universe. In the case of closed space, the universe (either the whole or the observable metagalaxy) must inevitably return to the initial state of nuclear fluid, and the universe would oscillate without external loss, "implying an unlimited age in the past and in the future". While some have expressed disgust at the idea of an oscillating universe, Öpik cannot see why it should claim a less æsthetic value than the annual succession of seasons, so praised by poet and layman.

\section{EFFECT OF INCLUSIONS ON STEEL}

$\mathrm{T}$

HAT the mechanical properties of test pieces of steel cut transversely to the direction of working are inferior to those cut longitudinally has been recognized for very many years. Further, it is implicit in many specifications that the process by which a steel has been manufactured exerts its influence on the properties. It is well recognized that the inclusions present play a substantial part in determining the difference of properties in the trans verse and longitudinal directions; but it may be doubted whether the mere presence of such inclusions could of itself offer an adequate explanation of all the facts. Why the steelmaking process should have an influence is still a matter largely of speculation, though the gases present-oxygen, hydrogen and nitrogen-and their amounts have been suggested as playing a predominating part.

The Iron and Steel Institute, in Special Report No. 50, has published a paper by Mr. P. H. Frith, on "Fatigue Tests on Rolled Alloy Steels made in Electric and Open-Hearth Furnaces" *, which forms a report of the Fatigue and Inclusions Committee of the British Iron and Steel Research Association. A part of this work was carried out under the auspices of the Inclusions Sub-Committee of the Iron and Steel Institute, formed in 1936, at the instigation of the late Dr. W. H. Hatfield, to investigate the practicability of measuring the standard of cleanliness of aircraft steels by means of some numerical count. It was soon apparent that the grading of steels by this inclusion count method did not necessarily coincide with that based on mechanical properties, and an extensive programme of fatigue tests has been carried out, mainly by the Bristol Aeroplane Co., Ltd. An enormous amount of work has been put into this investigation, which, in some directions, is one of the most important contributions to our knowledge of the factors determining the properties of steel for very many years.

The steels examined were heat-treated to give tensile strengths of $60-110$ tons/sq. in. Up to the former strength, the inclusions of the size and type normally present do not appear to exert any particularly detrimental effect, though accidental inclusions of more massive form are probably harmful. As the strength of $a$ steel is increased, however, the effects of the inclusions grow progressively more serious, particularly in reducing the resistance to

* Iron and Steel Institute Special Report No. 50: Fatigue Tests on Rolled Alloy Steels made in Electric and Open-Hearth Furnaces. By P. H. Frith. Pp. vii $+130+22$ plates. (London: Iron and Steel Institute, 1954.) 25s., or 15s. to members of the Institute. fatigue. One of the most outstandingly important observations made during the course of this work seems to be the profound influence exerted by the shape and deformability of the inclusions, which therefore are divided into three groups: (1) those which deform during hot-working and become elongated; (2) those which do not deform; and (3) those undeformed inclusions of Group 2 which have a deformable envelope of manganese sulphide.

From the point of view of the stress concentration which results, it is believed that the undeformable inclusions of Group 2 are those which are most detrimental to the fatigue properties. These include hard angular fragments of alumina or alumino-silicates, titanium cyano-nitride, quartz and spherical silicates. It also appears from these tests that, in any event up to 0.04 per cent sulphur, the fatigue properties are not affected by the number of manganese sulphide inclusions so long as this sulphide does not form part of a duplex aggregate. This emphasis on the importance of the plastic properties of the inclusions is supported by the fact that the reduction in the fatigue limit in the transverse direction cannot be directly correlated with the sulphur, oxygen or phosphorus content of the steel, either singly or combined.

In addition to the normal metallographic examination, microradiographs, magnetic tests, etc., were also employed, the importance of the first of these lying in the fact that, although the surface inclusions appear to play no particularly harmful part, there is good evidence that inclusions lying just below the surface, for some reason or other, may, and apparently often do, act as the starting-point for fatigue cracks. In certain steels, particularly basic electric, inclusions of an apparent diamond shape are not uncommon. Careful investigation has shown that the actual inclusion in such cases is itself more or less spherical, but that during the working operation 'cavities' are formed in front and behind, and these apparently may play a profound part in initiating fatigue. It would appear, therefore, that we have here at any rate a partial explanation of the influence of the steelmaking process employed, since open-hearth steels appear to be less prone to contain these hard spherical inclusions than is that made by the basic electric process.

The author has spent many years on this work, and he and the Bristol Aeroplane Co., Ltd., deserve most sincere thanks for the light which is thrown on a problem of the greatest importance to all those who make and who use the higher-tensile steels.

F. C. Thompson

\section{STANDARDIZATION OF WOUND TEXTILES}

By DR. HEINZ BARON

Surgical Clinic of the Medical Academy, Düsseldorf

$\triangle \mathrm{S}$ a preliminary to any discussion on the stanA dardization of wound textiles, a brief discussion is necessary as to whether wound textiles are, in fact, true healing agents. My own work has shown that suppuration and cedema of the surrounding tissue results when a wound is covered by a 'Plexiglass' capsule (Baron) (see Figs. $1 a$ and $\mathbf{l} b$ : the wound rises into the hollow space of the capsule). The effect is 